\title{
The Realization of Ideals \\ Concerning Family Size
}

\author{
MARKETTA RITAMIES
}

The Population Research Institute

OLAVI RIIHINEN

Department of Social Policy

University of Helsinki

HELI PENTTINEN

AIMO PULKKINEN

The Population Research Institute

The goal of family planning is, according to one definition, for every child to be born a wanted child and when it is most convenient for the family. On the other hand, family planning is also supposed to enable couples to have the number of children they desire. These two goals do not fully coincide, however.

In many countries family planning programs which prevent undesired pregnancies are used in enabling children to be born wanted. These same programs have not, however, been able to aid couples in reaching their desired family size. The reason for this contradictory situation is that there are two kinds of couples who have not been able to have a family the size they consider ideal. It is not only the couples who have more children than they had hoped for whose goal has not been reached, but also couples who have a smaller family than they had desired.

When, after World War II, the birth rate was still high even in developed countries, efforts were made to decrease the fertility level by preventing undesired births. In the United States varied calculations were made to determine what it would mean for population growth for all children to be born wanted. During this period of high fertility researchers paid hardly any attention to the possibility of there being couples with fewer children than they had desired. "Excess fertility» was a common topic in the demographic literature, »deficit» fertility was not. (Weller 1974, 79).

When the birth rate started to decline strongly in the mid-1960s and as it gradually stabilized at a relatively low level in the 1970 s, it was no longer as important demographically to ponder the significance of undesired pregnancies for population development. A more pressing question for many decision makers was how to affect the birth rate so that the population's reproduction level would be preserved. 
This problem could not be solved with family planning programs that eliminated undesired pregnancies. However, considering the humanitarian goal of family planning, it continued to be important to strive to ensure that every child be born a wanted child. The unfavorable effects of undesired pregnancies have been seen, for example, in forced marriages, illegitimate births, as a denial of educational and occupational opportunities, in poverty, and the restricted roles of women (Weller-Hobbs 1978, 168).

From a population policy viewpoint, however, interest arose in couples who did not have as many children as they would have desired. This group may imply potential births. Davies $(1967,732)$ noted at the end of the 1960s that people in industrialized countries usually have fewer children than they desired and that the situation in the developing countries is the opposite. In other words, he confirmed what had been stated by Stoetzel already in the 1950s. Up till then, ideals had been considered smaller than the actual number of children, but already then the situation in Europe was the reverse (Hawthorn 1970, 15-16).

In some studies it has been found that the proportion of women with fewer children than they had desired was at least as high as those with more children than they desired (Whelpton et al. 1966, 53, Woolf 1971, 34 and Weller 1974, 79). Because the group was so large, it was probable that, in addition to persons with fertility problems, the group consisted also of couples who had consciously planned to have fewer children than they desired.

In Finland, also, the birth rate started to decline in the mid-1960s and stabilized in the following decade at 13 to 14 per thousand. Even though Finland has no officially stated population policy goal, stable population development has implicitly been considered its goal. There have also been no family planning programs, but by using guidance and information, efforts have been made so that every child could be born a wanted child.

The realization of one's desired family size and the prevention of undesired pregnancies need not be contradictory aims, as long as differing measures are used to attain them. By improving information about contraception and guaranteeing the availability of effective contraceptives, we can try to decrease the number of undesired pregnancies. Various social development policy measures, again, could be used in striving for a situation where every couple could realize their own ideal concerning family size and would not have to resign themselves to having fewer children than they had hoped for. However, this demands that we know who the persons are who end up with fewer children than they had desired and whether their characteristics differ from those of couples who exceed their desired family size.

This article will examine various types based on how ideal concerning family size has been realized. Their characteristics and differences will be examined according to variables found in previous studies (for example, Weller 1974, Weller-Hobbs 1978) to correlate with different kinds of fertility behavior. We wish to discover whether couples who have fewer or more children than they desired differ from couples who have realized their ideal. 
This article is based on research which formed Finland's part of the World Fertility Survey. The data was composed of 19-45-year-old women who were married for the first time. These women were interviewed in 1977. The sample totalled 6200 women, of whom 5449 were included in the final data.

\section{Forming the ideal typology}

The realization of ideals held by Finnish families concerning family size will be examined according to a typology formed on the basis of the desired number of children and the expected number of children. The desired number of children is seen as representing the couple's personal ideal concerning family size and the expected number of children, again, is seen as predicting their final number of children. These two ideals concerning family size form the main dimensions of family size used in this typology. The two family size ideals of each woman will be compared to each other and, using this as a basis, a classification of various types of fertility behavior will be formed.

This analysis includes all women who answered both questions concerning ideal family size. Only $4 \%$ of the women interviewed gave no answer to the question concerning desired family size. On the other hand, it was not possible to form an expected number of children for $19 \%$ of the women. Sterile women for whom expected family size was not calculated were excluded from the examination, as were women who could not say whether they still expected to have more children or not. Expected family size was formed by adding the number of children already born to the number of children the woman still expected to have in the future.

The data being examined perhaps does not fully represent all of the women interviewed. Apparently 25-34-year-old women with two children and who have passed the matriculation examination are slightly underrepresented in the data. In addition, it must be taken into account that desired family size may to some extent represent an unrealistic ideal. The question »If you could choose the exact number of children you would desire the most» perhaps does not reflect the number of children the woman interviewed would have wished to have at the time of the interview. The ideal may more likely represent a liking for children in general.

Desired family size should, on one hand, signify a number of children uncorrelated with one's existing number of children. Research results point to the possibility, however, that the number of children a couple already has influences the number of children desired (for example, Ryder 1973, 495-506). The correlation of 0.41 between desired and expected family size would not, however, according to the conclusions presented by Weller $(1974,86)$ signify in Finland, either, as much a rationalization of one's answers as it would the couple's goal, which reflects their ideal.

The women included in the analysis were distributed into types congruent with or deviating from their ideal according to the following tabulation. Women whose family size is congruent with their ideal have been divided, in addition, into two 
groups on the basis of whether they had wanted a small family of one or two children or a large family of at least three children.

\begin{tabular}{|c|c|c|c|c|}
\hline \multicolumn{5}{|c|}{ Ideal typology } \\
\hline $\begin{array}{c}\text { More than } \\
\text { ideal }\end{array}$ & $\begin{array}{c}\text { Large family } \\
\text { congruent with } \\
\text { ideal }\end{array}$ & $\begin{array}{l}\text { Small family } \\
\text { congruent with } \\
\text { ideal }\end{array}$ & $\begin{array}{c}\text { Fewer } \\
\text { than ideal }\end{array}$ & Total \\
\hline 16.5 & 22.3 & 42.1 & 19.1 & 100 \\
\hline 721 & 978 & 1847 & 838 & 4384 \\
\hline
\end{tabular}

People who realized their ideal of a small family formed the majority in the analysis, while people who exceeded their ideal formed the smallest group. This is a clear indication of the fertility development which has occurred in the developed countries. The small family ideal has been commonly accepted and it is also realized. The proportion exceeding their ideal has shrunk as people are better informed about contraception and as the use of contraceptive methods increases.

An article based on data from the national fertility survey made in the United States in 1965 found that for $55 \%$ of the women interviewed desired and expected family size were the same. Desired family size was smaller than the expected size for $18 \%$ and greater for $27 \%$ (Weller 1974, 79). Ideal family size was measured with questions similar to those used in our survey. Such a long time has elapsed since the data was collected, however, that ten years later the situation is not likely to be the same as that described in the article, even in the United States.

At the aggregate level the realization of ideal concerning family size among Finnish women would not cause any changes in family size, as the desired family size and expected family size were the same for the women in the analysis, an average of 2.4 children. In the United States in the mid-1960s the average difference between these two family sizes was 0.3 children. There the realization of ideal family size would have decreased the average number of children from 3.54 to 3.25 (Weller 1974, 79-80).

In the United States the average number of children would drop to 2.96, if women who exceeded their ideal did not have as many children as they expected, and instead realized their ideal and, correspondingly, if those with fewer children than their ideal did not realize their ideal and instead had as many children as they expected. In Finland a corresponding change would mean as decline in the number of children to 2.2. This average would mean a definite decline in fertility and would not be sufficient to guarantee a level of reproduction. An average of 2.56 children per mother should be born, in order that the population would renew itself (Lindgren 1975, 53).

Despite the average similarity between desires and expectations, there were naturally marked differences regarding desired and expected family size among the various types of ideals. The ideal family size of people who exceeded their ideal was small, but they expected to have more children than the others did, which was demonstrated by the large number of children they already had (Table 1). 
$\mathrm{T}$ a b 1 e 1 . Desired and expected family size and average number of existing children according to type of ideal

\begin{tabular}{cccc}
\multicolumn{4}{c}{ Type of ideal } \\
$\begin{array}{c}\text { More than } \\
\text { ideal }\end{array}$ & $\begin{array}{c}\text { Large family } \\
\text { congruent }\end{array}$ & $\begin{array}{c}\text { Small family } \\
\text { congruent }\end{array}$ & $\begin{array}{c}\text { Fewer } \\
\text { than }\end{array}$ \\
& with ideal & with ideal & ideal
\end{tabular}

Existing number of children

2.5

1.3

1.3

1.8

Desired number

of children

2.0

3.3

1.9

2.9

2.4

Expected number

of children

3.5

721

3.3

1.9

1.6

838

Total

978

1847

2.4

4384

The ideal family size of persons with fewer children than their ideal, on the other hand, was large, but they expected to have fewer children than the others and the number of children they already had was also small. Naturally, the desired family size of persons realizing a small family ideal was smaller than that of persons realizing a large family ideal. The difference between the ideal family sizes of these two types was 1.4 children (Table 1).

The results found in the United States were similar, although family size was definitely greater (Weller 1974, 79), which is due naturally to the interviews having taken place over ten years previously and to the larger family model, compared to Europe, dominant in the United States.

\section{The characteristics of the ideal types}

The characteristics of the ideal types are described on the basis of various demographic and socio-economic variables. These variables have been used in previous studies to demonstrate various kinds of fertility behavior (for example, Weller 1974, $80-82)$.

\section{Life phase and type of ideal}

Demographic variables such as the number of existing children, the wife's age and the length of the marriage are used in comparing congruent and deviating types of ideals. These variables are closely related to the interviewee's life phase and are closely interrelated with the formation of the types.

Weller's (1974) statement »the more children a woman has the more likely she is to exceed her ideal and the less likely she is to have fewer than her ideal» is selfevident and is apparent in this study also. The number of existing children affects the type the woman belongs to. When a woman has many children, she is not often a woman with fewer children than her ideal and never a woman realizing a small family ideal. 
On the basis of the averages, the differences in family size between the ideal types were statistically extremely significant, except for women with fewer children than their ideal and women with a small family congruent with their ideal, both of whom had the same number of children (Table 2).

$\mathrm{T}$ a b l e 2. Average number of existing children, wife's age, length of marriage, wife's education (in years), family's net monthly income, husband's socio-economic status, region and significance of religion by types of ideal

Type of ideal

$\begin{array}{ccccc}\begin{array}{c}\text { More than } \\ \text { ideal }\end{array} & \begin{array}{c}\text { Large family } \\ \text { congruent }\end{array} & \begin{array}{c}\text { Small family } \\ \text { congruent }\end{array} & \begin{array}{c}\text { Fewer } \\ \text { than }\end{array} & \text { Mean } \\ & \text { with ideal } & \text { with ideal } & \text { ideal }\end{array}$

Existing number

$\begin{array}{lrrrrr}\text { of children } & 2.7 & 2.5 & 1.3 & 1.3 & 1.8 \\ \quad \text { St.d. } & 1.5 & 1.2 & 0.7 & 0.9 & 1.2 \\ \text { Wife's age } & 34.0 & 33.5 & 32.1 & 35.0 & 33.5 \\ \quad \text { St.d. } & 7.0 & 7.0 & 6.5 & 6.3 & 6.8 \\ \text { Length of marriage } & 12.3 & 11.8 & 9.5 & 12.7 & 11.1 \\ \quad \text { St.d. } & 7.1 & 7.1 & 6.3 & 6.2 & 6.8 \\ \text { Wife's education } & & & & & 10.0 \\ \text { (in years) } & 9.4 & 10.0 & 10.2 & 10.2 & 2.6 \\ \quad \text { St.d. } & 2.2 & 2.7 & 2.7 & 2.8 & 3068 \\ \begin{array}{l}\text { Family's net monthly } \\ \text { income, Fmk }\end{array} & 2816 & 3003 & 3123 & 3239 & 1300 \\ \quad \text { St.d. } & 1282 & 1422 & 1226 & 1290 & 0.92 \\ \text { Husband's } & & & & & 0.3 \\ \text { socio-economic status } & 0.89 & 0.88 & 0.95 & 0.93 & 1.8 \\ \quad \text { St.d. } & 0.3 & 0.3 & 0.2 & 0.3 & 1.1 \\ \text { Significance of } & & & & & 1.7 \\ \text { religion } & 1.7 & 1.6 & 1.9 & 1.1 & \\ \quad \text { St.d. } & 1.1 & 1.1 & 1.0 & & \\ \quad\end{array}$

The women who exceed their ideal and had the largest number of children, on the average, were distributed rather evenly according to family size. Except for the childless, they included almost as many two-, three- and at least four-child families. The proportion with one child was also quite large. The next largest group regarding average family size, those realizing a large family ideal, differed from women exceeding their ideal most clearly in that this group included the greatest number of three-child families. On the other hand, there were fewer families with at least four children or only one child (Table 3 ).

The most distinct difference between the smallest families, on the average, or those with fewer children than their ideal, and those with a small family congruent with their ideal was that there were more childless and one-child families among 
those with fewer children than their ideal, while those realizing their ideal were more often two-child families (Table 3).

T a b l e 3. Number of existing children, wife's age and duration of marriage according to ideal type as a percentage

\begin{tabular}{lccccccc} 
& \multicolumn{7}{c}{ Number of existing children } \\
MI & 0 & 1 & 2 & 3 & $4+$ & Total & N \\
LFCI & $(1.5)$ & 20.4 & 26.2 & 25.2 & 26.6 & 100 & 721 \\
SFCI & 5.8 & 13.9 & 26.5 & 40.2 & 13.6 & 100 & 978 \\
FI & 15.2 & 37.0 & 47.8 & - & - & 100 & 1847 \\
Total & 18.9 & 42.1 & 31.5 & 6.4 & 1.1 & 100 & 838 \\
N & 11.5 & 30.1 & 36.4 & 14.4 & $(7.6)$ & 100 & \\
& 506 & 1320 & 1595 & 629 & 334 & & 4384
\end{tabular}

Ideal type

MI $=$ More than ideal

LFCI = Large family congruent with ideal

SFCI $=$ Small family

congruent with ideal

$\mathrm{FI}=$ Fewer than ideal

Total

$\mathrm{N}$

\begin{tabular}{ccccccc}
\multicolumn{7}{c}{ Wife's age } \\
$19-24$ & $25-29$ & $30-34$ & $35-39$ & $40-45$ & Total & N \\
9.2 & 21.9 & 21.8 & 18.6 & 28.6 & 100 & 721 \\
& & & & & & \\
10.7 & 23.6 & 21.6 & 17.8 & 26.3 & 100 & 978 \\
& & & & & & \\
13.2 & 25.4 & 26.7 & 17.7 & 17.1 & 100 & 1847 \\
5.9 & 13.0 & 18.9 & 27.6 & 34.3 & 100 & 898 \\
10.6 & 22.1 & 23.2 & 19.7 & 24.4 & 100 & \\
464 & 967 & 1019 & 865 & 1069 & & 4384
\end{tabular}

\begin{tabular}{|c|c|c|c|c|c|c|c|}
\hline & \multicolumn{6}{|c|}{ Duration of marriage } & \\
\hline & Years & -5 & $5-9$ & $10-14$ & 15 & Total & $\mathrm{N}$ \\
\hline MI & & 19.0 & 24.1 & 18.5 & 38.4 & 100 & 721 \\
\hline LFCI & & 22.4 & 23.3 & 18.9 & 35.4 & 100 & 978 \\
\hline SFCI & & 30.4 & 27.4 & 20.4 & 21.8 & 100 & 1845 \\
\hline FI & & 14.7 & 19.5 & 28.3 & 37.6 & 100 & 838 \\
\hline Total & & 23.7 & 24.4 & 21.3 & 30.6 & 100 & \\
\hline $\mathrm{N}$ & & 1040 & 1070 & 931 & 1341 & & 4382 \\
\hline
\end{tabular}

Because family size is strongly correlated with the wife's age and the duration of the marriage, the assumption can be made that women who have exceeded their ideal are old and have been married for a long time and those with a small family congruent with their ideal are young and have been married for a short time. However, women with fewer children than their ideal probably form a type which, despite the small number of children, includes old women who have been married for a long time. It is obvious that the decision to have fewer children than one's ideal is made at a relatively late phase of life. Women who have had difficulties becoming pregnant hope for a child until the end of their childbearing period. People who for some other reason have postponed having children may plan to have children when the other factors in the way of having children have been removed. 
The results of this study support the assumptions presented. Women who had fewer children than their ideal were the oldest, on the average, and had been married for the longest time. The difference compared to the younger women with a small family congruent with their ideal was 3.8 years in age and 3.2 years in length of marriage. Women who had exceeded their ideal had also been married for a long time, but they were younger than the women with fewer children than their ideal, which means that they had married at a younger age (Table 2).

The frequency distributions demonstrate more clearly than the averages what kind of couples are found in each ideal type. The large deviations show that each type includes different-aged women and women who have been married for differing lengths of time.

The group with fewer children than they desired was mainly composed of women in the two oldest age groups and included fewer women from the younger age groups than the other types. The women exceeding their ideal and those with a large family congruent with their ideal included a large number of $40-45$-year-olds, but, on the other hand, fewer 35-39-year-olds. The youngest women were most frequently found among those realizing a small family ideal. The group with the large family they had desired also included young women. (Table 3).

The differences in duration of marriage corresponded to the differences in the wife's age. Women with fewer children than they desired included the most women married for at least ten years, However, women exceeding their ideal included the most women married for at least 15 years. The group realizing a small family ideal had the most women married for a short time, but women realizing their ideal of a large family also included a large number who had been married for a short time.

The three demographic factors examined here show how belonging to a certain ideal type is related to the life phase one is in. Although in a cross-sectional study each type of ideal naturally includes women of all ages, women who have been married varying lengths of time and also different-sized families, it was nevertheless clear to see how women with fewer or more children than their ideal were in a later phase of life than women realizing their ideal. Because these factors are essential prerequisites in the formation of the various types, no attempt will be made in this brief article to standardize these factors.

\section{Socio-economic factors and type of ideal}

In addition to features linked with one's phase of life, the ideal types will also be examined using various socio-economic variables reflecting differing fertility behavior. Especially the wife's education, family income and the husband's socioeconomic status have been found in previous studies (for example, Weller 1974) to correlate with actual and desired family size. Regional factors and the significance of religion have also been found to be important.

Weller $(1974,80-81)$ found the following correlation between education and type of ideal: the persons with fewer children than their ideal were the most highly edu- 
cated and those exceeding their ideal were the least educated. This analysis also shows that the education of persons exceeding their ideal differed from the education of other groups. They had the fewest years of schooling, 9.4 years on the average, while in no other type did the average go below ten years. The difference was extremely significant statistically (Table 2 ).

The women exceeding their ideal mainly had an elementary school education and all more highly educated groups were smaller here, with one exception, than in the other types. Although the average length of schooling was the same among those realizing a small family ideal and those with fewer than their ideal, they nevertheless differed from each other in that the latter group included more with an elementary school education or with an academic degree, and in the former a second level education was more common. Among those realizing a large family ideal there was, on one hand, a large number with an elementary school education and on the other hand, also more people with an academic degree than among those exceeding their ideal (Table 4).

Education has been found to correlate strongly with income and socio-economic status. Therefore one can assume that people with fewer children than their ideal and people who have realized their ideal of a small family will differ because of their higher level of income and higher socio-economic status from people exceeding their ideal and people who have realized a large family ideal. Weller's $(1974,81)$ results supported this assumption.

The income distribution of both ideal types with a higher income were similar. This was also true of both of the lower income types. However, among those realizing their ideal, be it a small or a large family, there were slightly more women in the higher income brackets than among those with more children than their ideal (Table 4).

The ideal types were distributed according to income into two groups. This is also apparent regarding the socio-economic status of the husbands. Women realizing a small family ideal and women whose family was smaller than their ideal had a higher average socio-economic status, while those realizing a large family ideal and those exceeding their ideal had a lower socio-economic status. The differences between both groups were statistically significant on at least the 0.1 percentage level. In addition, the difference between the types with a higher status was almost significant statistically (Table 2).

The differences between those realizing a small family ideal and those with a smaller family than their ideal was mainly due to the fact that the latter group included slightly more own-account workers, managers and higher administrative or clerical employees, while the former group included more lower administrative or clerical employees and skilled workers. Both types representing lower socio-economic status included a large number of own-account.workers. The difference between the types was apparent mainly in that those realizing a large family ideal included more managers and higher and lower administrative or clerical employees, while those exceeding their ideal included more skilled workers (Table 4). 
$\mathrm{T}$ a b l e 4. Wife's education, the family's total net monthly income and the husband's socio-economic status according to type of ideal as a percentage

\begin{tabular}{|c|c|c|c|c|c|c|c|c|}
\hline & $\begin{array}{l}\text { Elem. } \\
\text { school } \\
\text { at most }\end{array}$ & $\begin{array}{l}\text { Elem. sch. } \\
\text { voc. sch. }\end{array}$ & $\begin{array}{l}\text { Lower } \\
\text { sec.sch. }\end{array}$ & $\begin{array}{l}\text { Lower } \\
\text { sec.sch. } \\
\text { voc.sch. }\end{array}$ & $\begin{array}{c}\text { Lower } \\
\text { sec.sch. } \\
\text { tech. } \\
\text { college }\end{array}$ & $\begin{array}{l}\text { Matr. } \\
\text { exam. } \\
\text { voc. } \\
\text { sch. }\end{array}$ & $\begin{array}{l}\text { Matr. } \\
\text { exam. } \\
\text { tech. } \\
\text { coll. }\end{array}$ & $\begin{array}{l}\text { Acad. } \\
\text { degree }\end{array}$ \\
\hline MI & 56.5 & 17.1 & 7.6 & 3.9 & 4.4 & $(3.6)$ & (3.8) & (3.1) \\
\hline LFCI & 44.0 & 18.0 & 11.3 & 3.6 & 5.9 & 5.4 & 5.0 & 6.5 \\
\hline SFCI & 39.0 & 19.0 & 12.0 & 4.0 & 9.3 & 3.7 & 6.7 & 6.5 \\
\hline $\mathrm{FI}$ & 43.8 & 18.3 & 10.5 & 1.9 & 7.3 & 3.7 & 6.6 & 8.0 \\
\hline Total & 43.9 & 18.3 & 10.8 & 3.5 & 7.4 & 4.1 & 5.8 & 6.3 \\
\hline $\mathrm{N}$ & 1923 & 802 & 474 & 152 & 322 & 179 & 254 & 274 \\
\hline
\end{tabular}

Family's total net monthly income

$\begin{array}{lcccccccr} & -1000 & 1001- & 2001- & 3001- & 4001- & 5001+1 & \text { Total } & \text { N } \\ & & 2000 & 3000 & 4000 & 5000 & & & \\ \text { MI } & 6.4 & 24.7 & 27.6 & 27.7 & 9.6 & (4.0) & 100 & 656 \\ \text { LFCI } & 5.9 & 21.6 & 25.8 & 28.5 & 11.3 & 6.9 & 100 & 898 \\ \text { SFCI } & 3.6 & 16.6 & 26.9 & 35.1 & 12.8 & 5.1 & 100 & 1686 \\ \text { FI } & (3.1) & 14.9 & 25.2 & 35.9 & 14.1 & 6.8 & 100 & 766 \\ \text { Total } & 4.5 & 18.7 & 26.5 & 32.6 & 12.2 & 5.6 & 10 & \\ \text { N } & 179 & 749 & 1060 & 1305 & 487 & 226 & & 4006\end{array}$

1 Persons with no income are included in these calculations, which causes these income levels to be low.

Husband's socio-economic status

\begin{tabular}{|c|c|c|c|c|c|c|c|c|c|c|}
\hline $\begin{array}{l}\text { Other } \\
\text { than } \\
\text { agric. } \\
\text { own- } \\
\text { account } \\
\text { worker }\end{array}$ & $\begin{array}{c}\text { Agric. } \\
\text { own- } \\
\text { account } \\
\text { worker }\end{array}$ & $\begin{array}{l}\text { Manager, } \\
\text { higher } \\
\text { admin. } \\
\text { or cler. } \\
\text { employee }\end{array}$ & $\begin{array}{l}\text { Lower } \\
\text { admin. } \\
\text { or cler. } \\
\text { employee }\end{array}$ & $\begin{array}{l}\text { Skilled } \\
\text { worker }\end{array}$ & $\begin{array}{l}\text { Unskilled } \\
\text { worker }\end{array}$ & $\begin{array}{c}\text { Assist. } \\
\text { family } \\
\text { member, } \\
\text { non- } \\
\text { agric. }\end{array}$ & $\begin{array}{c}\text { Assist. } \\
\text { family } \\
\text { member } \\
\text { in } \\
\text { agric. }\end{array}$ & Student & $\begin{array}{c}\text { Un- } \\
\text { known }\end{array}$ & $\mathrm{N}$ \\
\hline 9.4 & 11.5 & 11.4 & 16.9 & 45.8 & (3.3) & (0.1) & - & (1.1) & 0.4 & 721 \\
\hline 10.8 & 11.7 & 16.0 & 18.9 & 37.3 & 2.3 & - & - & 2.5 & 0.6 & 978 \\
\hline 7.1 & 5.1 & 17.0 & 23.2 & 42.3 & (2.1) & $(0.1)$ & $(0.1)$ & (2.2) & 0.9 & 1847 \\
\hline 7.9 & 7.3 & 18.0 & 22.7 & 39.5 & (3.2) & - & $(0.1)$ & $(0.8)$ & 0.5 & 838 \\
\hline 8.5 & 8.1 & 16.0 & 21.0 & 41.2 & (2.6) & $(0.1)$ & $(0.1)$ & (1.8) & 0.7 & \\
\hline 371 & 353 & 703 & 925 & 1808 & 112 & 2 & 2 & 79 & 29 & 4384 \\
\hline
\end{tabular}

The significance of region and religion in regard to the types

The regional characteristics of the types were examined with a regional distance variable. By cross-tabulating the variables »distance between the center of the municipality and Helsinki» and »distance between the center of the municipality and the regional center» we formed a 9-level variable, which we feel best demonstrates regional differences in a brief examination such as this. 
People realizing a small family ideal and those with a smaller family than their ideal more frequently lived closer to Helsinki or the regional center than those exceeding their ideal and those realizing a large family ideal. The latter two often lived in the sparsely settled regions of the country far from urban centers (Table 5).

Fertility surveys have shown that the ideal family size of religious families is greater than that of people whose attitudes toward religion are indifferent or actively negative, because among religious groups norms concerning family size are large and the significance of children for family life is emphasized. Thus one can probably assume that among those realizing a large family ideal there are more persons than in the other types who consider religion important, while among those realizing a small family ideal there are more who have an indifferent or negative attitude toward religion. People who had a smaller family than their ideal were found to be exceptional types in that their family size ideal was large. They, also, may include people with a positive attitude toward religion, who have not had as many children as they would have desired.

People who had desired and also had a large family proved to be the most religious, on the average, while religion had the least significance in the lives of people desiring and having a small family. People who exceeded their ideal did not differ significantly from those desiring and having a large family. On the other hand, the difference between those with a smaller family than their ideal and those realizing their ideal small family was extremely significant (Table 2).

Women with a small ideal-congruent family included the least for whom religion was very important or quite important. They also included the most who found it difficult to say how important religion was in their lives. The group with a large family congruent with their ideal included the largest amount of religious families and the fewest who were indifferent toward religion or uncertain about their attitude (Table 5).

\section{How do the ideal types differ from each other?}

The ideal types were found to differ clearly from each other according to the characteristics examined above. Nevertheless, for most variables two differing groups arose: those exceeding their ideal and those realizing their large family ideal, on one hand, and those with fewer children than their ideal and those realizing their small family ideal, on the other. Extremely significant differences were found between both groups.

A description of the characteristics of the ideal types using several variables would probably give a confusing picture of the situation. Therefore, we will attempt to narrow down the types into groups which best discriminate between them. A discriminant analysis will probably best suit this purpose.

A selective discriminant analysis was performed with 25 variables found in previous studies to be related to family size and ideals concerning family size. Ten variables were selected in the analysis (see Table 6). Three discriminating functions were 
$\mathrm{T} \mathrm{a} \mathrm{b} \mathrm{l}$ e 5. The distance between the municipal center and Helsinki and the regional center and the significance of religion according to type of ideal as a percentage

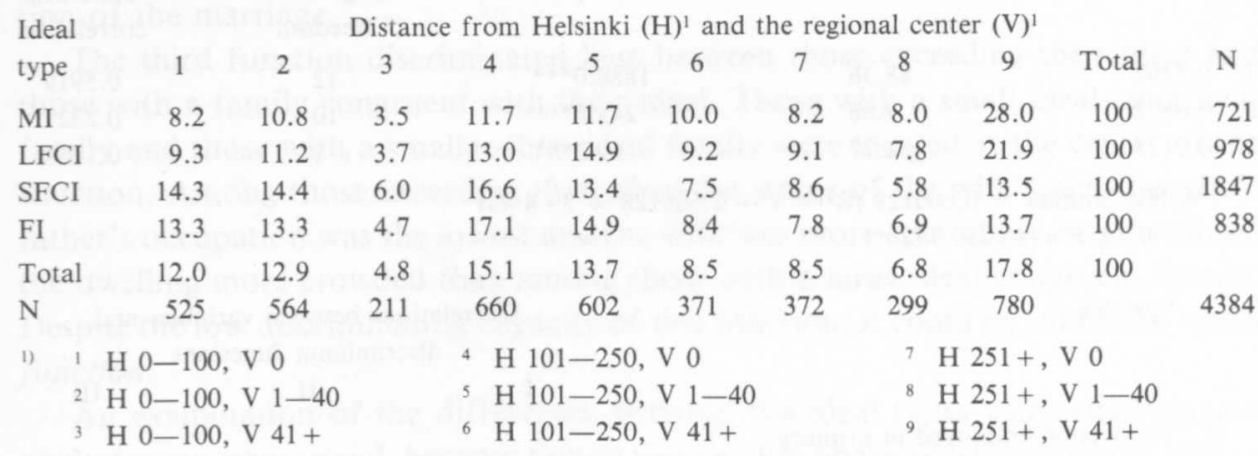

Significance of religion

$\begin{array}{lccccccr}\begin{array}{l}\text { Ideal } \\ \text { type }\end{array} & \begin{array}{c}\text { Very } \\ \text { important }\end{array} & \begin{array}{c}\text { Quite } \\ \text { important }\end{array} & \begin{array}{c}\text { Difficult } \\ \text { to say }\end{array} & \begin{array}{c}\text { Not very } \\ \text { important }\end{array} & \begin{array}{c}\text { Not at all } \\ \text { important }\end{array} & \text { Total } & \text { N } \\ \text { MI } & 12.2 & 35.6 & 23.7 & 25.2 & 3.2 & 100 & 721 \\ \text { LFCI } & 16.3 & 34.8 & 21.8 & 23.3 & 3.9 & 100 & 978 \\ \text { SFCI } & 7.5 & 30.3 & 28.1 & 29.3 & 4.7 & 100 & 1847 \\ \text { FI } & 12.9 & 35.0 & 21.7 & 25.8 & 4.7 & 100 & 838 \\ \text { Total } & 11.3 & 33.1 & 24.8 & 26.6 & 4.3 & 100 & \\ \text { N } & 494 & 1450 & 1085 & 1168 & 187 & & 4384\end{array}$

found, all of which were extremely significant statistically. Canonical correlations were low, however, except for the first function, which means that the groups overlap. The first two functions explained almost all of the total discrimination: the first function alone explained a total of $88 \%$.

The first function had a significant negative correlation with family size. In addition, the function had a weak correlation with the portion employed in primary production. Those with a smaller family than their ideal and those with a small idealcongruent family received high values in this function. Those exceeding their ideal and those with a large ideal-congruent family were located close to each other at the opposite end of the function (Appendix Figure).

This first function is closely connected with family size, even though it also has a weak correlation with the proportion employed in primary production. The function showed how the ideal types were clearly distributed into two groups. Women with a small ideal-congruent family and women with a smaller family than their ideal had small families and lived in industrialized and service industry-dominated areas, while those exceeding their ideal and those with a large family congruent with their ideal had more children and lived in agricultural areas.

The effect of one's existing family size on the ideal type one belonged to was clearly apparent in the first family size function. The second function also supports the observations made above in connection with the description of the characteris- 
$\mathrm{T} \mathrm{a} \mathrm{b} 1$ e 6 . Discriminant analysis of ideal types formed according to desired and expected number of children

$\begin{array}{lrrcc}\text { Eigenvalue } & \text { Percent } & \text { Chi square } & \begin{array}{c}\text { Degrees of } \\ \text { freedom }\end{array} & \begin{array}{c}\text { Canonical } \\ \text { correlation }\end{array} \\ \text { 1. } 0.5392 & 88.36 & 1888.0^{* * *} & 12 & 0.5919 \\ \text { 2. } 0.0572 & 9.38 & 243.6^{* * *} & 10 & 0.2327 \\ \text { 3. } 0.0138 & 2.27 & 60.2^{* * *} & 8 & 0.1168\end{array}$

Wilks' lambda $=0,606128\left(\mathrm{R}^{2}=\mathrm{i}-0.606128=39.4 \%\right)$

$\mathrm{F}(30,++++) 79.542 * * *$

Variable

89. Number of children of wife's mother

257. Wife's current employment

261. Status of wife's occupation

359. Significance of religion

1121. Number of existing children

591. Duration of marriage

545. Wife's age
$-0.273$

$-0.146$

$-0.071$

$-0.145$

Correlations between variables and
discriminant functions

III

$-0.124$

$-0.146$

0.123

$-0.858$

$-0.120$

0.020

tics of the various ideal types. It is clearly a function related to phase of life and discriminates between the types mainly in regard to the wife's age and the duration of marriage, but also correlates with the size of the current dwelling, current family size, the significance of religion and the number of children the wife's mother had, all connected with one's phase of life.

This life phase function most clearly discriminated between persons with a smaller family than their ideal and those with a small family congruent with their ideal. Those with a large ideal-congruent family and those exceeding their ideal were located between these two at the center of the function. The function confirms the observations made above concerning the characteristics of the ideal types. Those with a smaller-than-ideal family were among the oldest and had been married the longest. They also had a large dwelling.

However, women with a smaller-than-ideal family and women with a small idealcongruent family did not differ from each other in relation to family size. Women who had exceeded their ideal and those with a large ideal-congruent family were in a life phase situated between these two types.

The first two functions explain such a large portion of the total discrimination that hardly any explanatory ability was left over for the third function. Appendix Figure clearly demonstrates the overlapping of the groups, although the function is still extremely significant statistically. 
The function had relatively high correlations with the status of the wife's and the wife's father's occupation. In addition, it had lower correlations with the current employment of the wife, the size of the current dwelling, the wife's age and the duration of the marriage.

The third function discriminated best between those exceeding their ideal and those with a family congruent with their ideal. Those with a small ideal-congruent family and those with a smaller-than-ideal family were located at the center of the function. Among those exceeding their ideal the status of the wife's and the wife's father's occupation was the lowest and the wife was more commonly employed and the dwelling more crowded than among those with a large ideal-congruent family. Despite the low discriminating capacity of this function, it could be called the status function.

An examination of the differences between the ideal types using discriminant analysis may seem trivial, because family size and life phase generally explain almost all of the total discrimination and no explanatory ability is left over for the third function. It might be useful to eliminate the effect of the existing number of children, but in a brief article like this this will be left undone.

This discriminant analysis was worthwhile because it demonstrated how closely the ideal types are related to family size and other factors connected with one's life phase. It clearly showed the dichotomy based on family size found in the ideal types: on one hand, those with a family smaller than their ideal and those with a small family congruent with their ideal and, on the other hand, those with a large family congruent with their ideal and those exceeding their ideal. At the same time it demonstrated how the types are located at different points on the dimension of time.

\section{Conclusions concerning the realization of ideals}

Among Finnish women over one-third felt at the end of the 1970s that they had not been able to realize their ideal. Over one-half of these women ended up with fewer children than they had hoped for, while the remainder exceeded their ideal. Nevertheless, at the aggregate level, desired and expected family size were the same.

As this article attempted to compare the characteristics of various ideal types and discover how the characteristics of women with more or fewer children than their ideal differed from women realizing their ideal, the examination revealed surprisingly how those realizing their ideal were in an earlier phase of life than the two groups deviating from their ideal, but otherwise resembled each other. Thus, in a way, two groups were formed, with the types in each group differing from each other in the same manner regarding socio-economic and regional variables and the variables measuring significance of religion.

The type with a family smaller than their ideal, assumed to be interesting from a demographic viewpoint, and the type exceeding their ideal - the focus of the humanitarian aim of family planning - were both in approximately the same phase of life, thus making it worthwhile to compare their characteristics. Correspondingly, 
those with a small ideal-congruent family and a large idea-congruent family formed a pair whose life phases resembled each other temporally. Their characteristics proved to be similar to those of persons with a smaller-than-ideal family and of exceeders, except that they were younger and had been married for a shorter time.

A comparison of the ideal types of the oldest group showed that people with a smaller-than-ideal family differed from the exceeders on the basis of the wife's higher education, the family's higher level of income and the husband's higher socioeconomic status. In addition, those with a smaller-than-ideal family lived closer to the Helsinki metropolitan area and the regional center than those exceeding their ideal, who lived in more sparsely settled regions. Religion, however, was more significant in both groups than on the average.

Persons with a small or large ideal-congruent family were in an earlier phase of life and differed from the previous types mainly in regard to their attitude toward religion. The group with a large idea-congruent family included most families who considered religion important. Those with a small ideal-congruent family, again, included the most with indifferent or negative attitudes toward religion. Otherwise the characteristics of the types resembled those of the previous group. The socioeconomic status of those realizing a small family ideal was higher than that of those realizing a large family ideal. They were better educated, had a higher income level, their status according to the husband's socio-economic position was higher and they lived closer to the Helsinki metropolitan area and the regional center.

The description of the characteristics of the ideal types was considered important because we could thus discover what the families are like whose opinions and behavior should be influenced, if one wished to change the prevailing fertility level. As those with a smaller family than their ideal and those exceeding their ideal proved to be at the stage where their childbearing period was coming to an end, their opinions can no longer be influenced. However, the types in the younger group include people who have not yet had all their children.

Nevertheless, it can be concluded on the basis of the characteristics of the ideal types in both groups that, in families in a good economic position, there are more women who have had few children and sometimes who have ended up with a smaller number of children than they had desired. A poor education, level of income and socioeconomic position, again, are related to a large number of children.

Some of those who have had a smaller family than their ideal have had to do so against their own will, while some have consciously planned their family size. Regarding those who have the small family they had desired, this may partially be the same thing. When one finds that it is not possible to have as many children as one desired, one decreases one's ideal accordingly. People do not want to admit that they have had difficulties getting pregnant.

Correspondingly, if someone has more children than she desired, this does not necessarily have to signify a failure in family planning any greater than the realization of a large family ideal. Some studies have shown that women with an elementary school education have been more honest in admitting undesired pregnancies. On the other hand, if in the same situation, people with a second level education may have 
increased their ideal. In this analysis the largest number of women with an elementary school education was found among those exceeding their ideal, while women who had the large family they had desired included more women with a higher education.

It remains for the decision makers to discuss how to influence families so that their fertility behavior would not be contrary to population goals. If stable population development is considered the goal, there should then be a discussion of how to influence couples, so that they could at least have as many children as they desire. This would also mean dealing with arrangements concerning the workplace and working hours and the development of child day care opportunities.

The humanitarian goal of family planning continues to necessitate efforts to influence at least those families in a weak socio-economic position in the use of contraceptives by improving guidance and information, so that an increasing number of children could be born wanted children and at the right time for the family.

A p pe n d i $\mathrm{x}$ i g u r e. Discriminant analysis of ideal types.
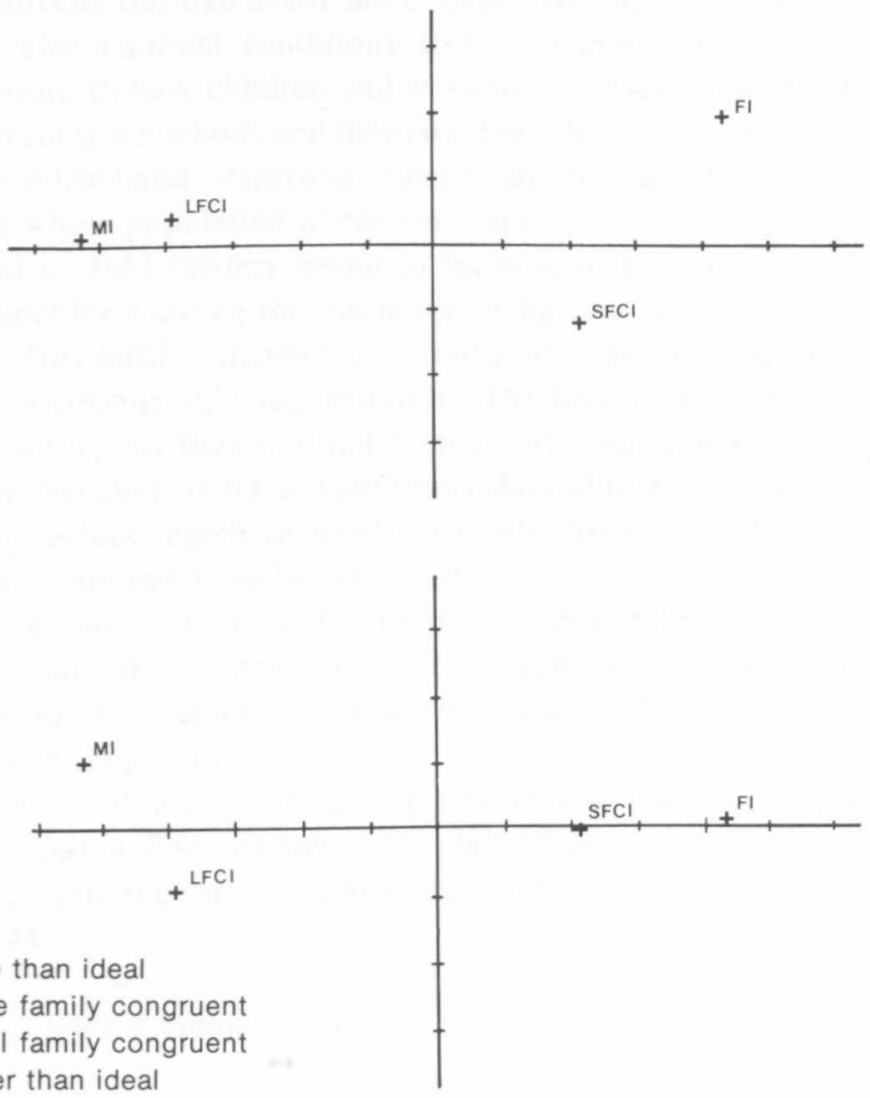

MI = More than idea

$\mathrm{LFCl}=$ Large family congruent

$\mathrm{SFCl}=$ Small family congruent

$\mathrm{FI}=$ Fewer than ideal 


\section{References}

Davis, Kingsley. (1967). Population policy: will current programs succeed? Science 158:730—739.

Hawthorn, Geoffrey. (1971). The sociology of fertility. Themes and issues in modern sociology. London.

Lindgren, Jarl. (1975). Suomalaisen syntyvyyden kehityskuva. Väestöntutkimuslaitoksen julkaisuja B:38. Helsinki.

Ryder, Norman B. (1973). A critique of the national fertility study. Demography, Vol. 10, 4:495-506.

Weller, Robert. (1974). Excess and deficit fertility. Social Biology 21:77-87.

\& Hobbs, F. (1978). Unwanted and mistimed births in the United States: 1968-1973. Family Planning Perspectives 10:168-172.

Whelpton, P. \& Campbell, A. \& Patterson, J. (1966). Fertility and family planning in the United States. Princeton.

Woolf, Myra. (1971). Family Intentions. London. 